\title{
LA ELECCIÓN DE LA LENGUA Y LA CREATIVIDAD LITERARIA EN AIMÉ CESAIRE
}

\author{
POR \\ JEAN BERNABÉ \\ Université Antilles-Guyane
}

Quisiera comenzar por descartar una serie de reproches sin duda precipitados que sitúan a Aimé Césaire no solamente como un anti-creole, sino incluso como un intelectual que en modo alguno hablaría la lengua de las grandes masas de Martinica, de la cual ha sido el portavoz durante cincuenta años. Y no he de olvidar, también, aquellas críticas que le reprochan el no haber escrito toda, o parte, de su obra en creole. Como si el grito cesairiano pudiera, en su inmediatez, adaptarse a una escrituralidad que aún no se ha construido. Como si la creación poética pudiera, en sí misma, ser una creación ex nihilo, separada entonces de cualquier fondo hipotextual. En cualquier caso, será necesario, en primer lugar, revisar algunas de las declaraciones del poeta sobre la lengua y la cultura creoles y resituarlas en la filosofía global de esos incansables promotores que son las sociedades resultantes de la trata de esclavos y la colonización. A continuación, será conveniente situar la esfera creole en el campo antropológico -particularmente antropoliterario- capaz de dar cuenta del lugar de este idioma en el universo creativo del poeta.

Jacqueline Leiner(1978) inicia su reedición de la revista Tropiques con una entrevista con Aimé Césaire. El siguiente diálogo evidencia claramente las informaciones que ella ha intercambiado con el poeta de la negritud sobre el tema del creole:

JACQUELINE LEINER: Otra pregunta que le habrán hecho: ¿si la revista hubiese estado escrita en creole, no hubiera alcanzado un público más extenso?

Aimé CÉSAIRE: Esta es una pregunta que no tiene sentido, porque una revista semejante no es concebible en creole.

JL: ¿Quienes hablan creole no tienen la necesidad de ser conscientes de sí mismos?

AC: No me refiero a eso. NOSOTROS tenemos siempre la necesidad de ser conscientes de nosotros mismos. Pero, ni Ménil ni yo hubiéramos sido capaces de escribirla en creole. ¡Eso es todo! Ni siquiera sé si es concebible. Parece usted sorprendida.

JL: ¿Entonces quienes hablaban francés eran los más descentrados?

AC: ¡No! ¡Para nada! ¡No sé si pueda ser siquiera formulado en creole, al menos dado el estado actual de la lengua! 
JL: ¿Entonces, esto se debe, en el fondo, a la estructura del creole?

AC: He hablado del retraso cultural martiniqués. Precisamente, un aspecto de ese retraso cultural es el nivel del idioma, de la creolidad si prefiere, el cual es extremadamente bajo, un idioma que quedó -y era aún más cierto en ese momento- en la etapa de la inmediatez, incapaz de alzarse, de expresar ideas abstractas. Es por esto que me pregunto si una obra semejante es concebible en creole. Y, además, para poder redactarla en creole las preguntas de base deberían haber sido resueltas. En primer lugar, la pegunta por legitimidad de la lengua. En segundo, que haya una gramática, una ortografía. El creole permanece únicamente como una lengua oral, que, de hecho, todavía no ha sido estructurada. La generación joven reflexiona sobre estos problemas. Pero en aquél momento no se consideraban. Nadie hubiese entendido la revista de haber sido escrita en creole. Hasta ahora, el creole se transcribe en francés, según reglas francesas. Sin embargo, el creole escrito a la francesa no se entiende, primero debe ser leído en voz alta, para transmitirlo al oído (1978).

Las respuestas de Césaire indican dos aspectos importantes: por un lado, una mirada llena de sentido común en relación con las potencialidades literarias todavía poco desarrolladas de una lengua exclusivamente oral, en este caso el creole. Por otro lado, una aproximación que, creo, revela más un déficit de pericia en cuanto al análisis de las lenguas, que un desprecio por hablar el creole, del cual Césaire dice, imprudentemente, que no tiene gramática. Como si fuera posible que una herramienta de comunicación, sin importar su estatus socio-lingüístico, pudiese escapar a la gramaticalidad. Tratándose de un hombre de la dimensión de Césaire, ciertamente podemos asombrarnos de que esta falta de pericia conduzca a criterios (habla, acordémonos, del "nivel de la lengua, de la creolidad [...] el cual es extremadamente bajo") más cercanos, digo, al punto de vista del común que a la visión del hombre culto. Pero, precisamente, conviene evitar toda precipitación, bajo el riesgo de malinterpretar la postura de Césaire. Postura que no se puede comprender sin recurrir detalladamente a la problemática antropológica -en particular antropo-lingüística-, que no solo sirve de base para el imaginario de la Negritud cesairiana, sino también para la formación intelectual, necesariamente inscrita en una cierta historicidad del cantor antillano de la Negritud.

Durante los años de formación de Aimé Césaire, la disciplina clave en el campo epistemológico de las ciencias humanas era la historia y dentro de ésta, la etnología. La búsqueda de la identidad se inscribía no tanto en la investigación de datos lingüísticos (Saussure), sino en un cuestionamiento de las estructuras antropológicas globales (LévyBruhl, Frobénius). Para Césaire -víctima del trauma de la esclavitud y la colonización-, la destrucción de la cultura generó en el Hombre antillano estragos considerablemente mayores que la eliminación de sus lenguas ancestrales ya que, más allá de estas lenguas, es natural el desarrollo de un catastrofismo trágico e irredentista en cuanto a la identidad 
cultural y, al mismo tiempo, una actitud más bien conciliadora y optimista en relación con el lenguaje. Césaire, adhiriéndose al principio de realidad, está obligado a hacer el duelo de la pérdida de las lenguas africanas por parte de los descendientes de esclavos, y entretanto, ha recuperado, incluso conquistado, una lengua sustituta, la lengua francesa, la cual, en su psique, parece funcionar como un verdadero botín de guerra.

Vividas en la dimensión de la pura subjetividad, las lenguas africanas asumen un carácter fantasmagórico, en franca correspondencia con el mito de una África unitaria. De este modo, a través de un poema como la "Prière au fleuve Congo" (Plegaria al río Congo), vemos al poeta inventar y re-inventar un idioma africano puramente ficticio, idioma que, al fijarse, queda en deuda con las influencias pre-surrealistas de un Tristán Tzara. La lengua ancestral perdida, adornada de prestigios compensatorios, no podía convertirse únicamente en un idioma aristocrático. En el poeta de la negritud, esta desaparición encuentra su contrapunto no en el registro del francés ordinario, sino en el del francés más majestuoso. La lengua cesairiana es, verdaderamente, el doble homológico y compensatorio de una lengua africana imposible, por estar perdida. La estilística de Césaire no se puede comprender si no se integra ese sutil proceso de transferencia que, en él, ha tenido lugar en el orden de lo simbólico. Por lo tanto, el creole, en tanto que lengua, desaparece del campo de la consciencia creadora (sino del inconsciente) del poeta. Esto se debe a tres razones:

1. Porque el creole es visto como la lengua del compromiso, a saber, del compromiso histórico con el colonizador, como la lengua de la derrota, de la capitulación, de la rendición.

2. Porque es una lengua que nació de amores auxiliares, a saber, de la violación, una lengua marcada por los estigmas de la esclavitud.

3. Porque es una lengua que ocupa, en la configuración socio-lingüística de nuestros países, un lugar menos prestigioso, como puede serlo en Francia el francés popular.

Es por esto que ninguno de estos dos registros puede acompañar o sostener un proyecto épico a la altura de la subversión que implica el grito cesairiano. Así pues, sólo el nivel más alto del francés puede construir, dentro de una economía que no es solamente la de la lengua sino del lenguaje, el antídoto fantasmal de la herida ocasionada por la pérdida de la lengua africana.

Cabe resaltar que esta concepción de carácter heroico, anterior a la elaboración misma del Cahier... (Cuaderno...), sobrevivirá al torbellino que este gran poema épico pone en marcha: sabemos que el narrador rechaza, en un momento dado, sus falsas glorias, sus obsesiones de liderazgo compensatorias de descendencia aristocrática, para recobrar la condición desnuda y miserable del "negro pongo". Allí hubiera podido descubrir las virtudes del creole, lengua del proletariado; ciertamente hubiera podido invertir su visión y encontrar, detrás de la realidad mestiza y del carácter bastardo de 
esta lengua, la supervivencia más pertinente y arraigada (así sea mestizada) de la madreÁfrica en las Antillas. En realidad, la visión épica de Césaire no es una visión inmanente sino verdaderamente trascendente. Sabemos que habrá que esperar el movimiento de la creolidad para que los héroes de la literatura antillana permanezcan como simples “djobeurs", personajes sin consistencia social, seres insignificantes y aun así provistos, en el orden de lo imaginario, de una extraordinaria significación.

La generación del Césaire estudiante no conoció el imperialismo de la lingüística, que se volvió, por medio del estructuralismo seguido del generativismo, la disciplinapiloto, la disciplina faro de las ciencias humanas y sociales. Césaire conservó de su formación, notoriamente pre-saussuriana, una consciencia filológica aguda, heredera de concepciones neogramáticas, centradas en enfoques históricos de los hechos lingüísticos. Para el poeta de la negritud, las discapacidades del creole son tales que no se le puede conferir una amplitud antropo-lingüística que fundamente una misión civilizadora o un papel motor en el desarrollo de nuestros países. Si volvemos a los términos de sus respuestas a las preguntas de Jacqueline Leiner, podemos constatar que son, en este sentido, muy elocuentes. Pero a la hora del progreso del creole, que hasta hace poco era impensable, lo admitiremos voluntariamente: solo una cierta demagogia, o aún ciertos dones proféticos, hubieran podido llevar a Césaire, teniendo en cuenta su formación intelectual y su relación con la escrituralidad, a otorgarle a una lengua tan minoritaria e infravalorada como lo es el creole, un papel tan crucial en las estrategias de desarrollo. Me parece que habría un gran anacronismo al sostener lo contrario.

Sin embargo, es apropiado reevaluar la concepción cesairiana, la cual es menos simplista de lo que parece a primera vista. En primer lugar, tratándose de la "bajeza" de nuestro vernáculo, expresión que se deriva del adjetivo "bajo" que Césaire atribuye al creole, cabe resaltar que este término no es totalmente ajeno a la terminología de los lingüistas. Estos últimos, en un vocabulario provisto de la neutralidad científica, establecen, en efecto, luego de Charles Ferguson (1959), una distinción, que se volvió célebre, (ya que fundó el concepto de diglosia) entre una lengua de nivel alto (el francés) y una lengua de nivel bajo (el creole). Para Derek Bickerton (1984), a quien le debemos una teoría igual de reconocida, la del bioprograma humano, donde los creoles serían las preciosas ilustraciones, es necesario establecer dos niveles del lenguaje (o niveles lectivos): el basilecto (o creole) y el acrolecto (o lengua estándar, de contacto, en este caso, el francés). Vemos entonces, que, aún si la terminología empleada por Césaire no está totalmente desprovista de connotaciones axiológicas, sigue siendo la expresión de la intuición de un no-especialista.

En primer lugar, debo dar cuenta rápidamente de la presencia de la matriz lingüística creole en la poesía de Aimé Césaire. En efecto, en contra de todos los prejuicios recibidos, era necesario mostrar que, mucho antes que los otros autores de la creolidad, el imaginario del poeta de la negritud se apoyaba en el uso de estructuras lingüísticas y retóricas 
propias de su lengua vernácula. A este respecto, ciertamente no sabríamos detenernos en el título de una de sus antologías poéticas, "Soleil cou coupé" (Sol cuello cortado), dado que Guillaume Apollinaire utiliza esta expresión de sintaxis extrañamente creole en su emblemático poema "Zone" (Zona), verdadero canto de una puesta en duda de la mirada europea sobre las culturas de África. En Césaire, se trata de una práctica que se encuentra lejos de ser insignificante y que no se limita a una sola obra.

Podemos citar los términos:

-“sabana" en Les Chiens (Los Perros)

"las sabanas se dividen en una gloria de locos penachos" (132)

-el adjetivo "viejo", que no se entiende como "viejo" sino como "feo":

"una vieja vida mentirosamente sonriente"

"una vieja miseria pudriéndose bajo el sol"

"un viejo silencio reventando de pústulas tibias"

-"un fardo" que debe entenderse con valor cuantitativo

"un fardo de escalofríos" (Les Chiens) (Los Perros)

"un fardo de agua sonora" (Cahier) (Cuaderno)

-empleo de la forma transitiva del verbo "estallar"

"su recaída vertiginosa que estallaba la vida de las casillas como una granada demasiado madura" (Cahier) (Cuaderno)

-tirar un pie

"tiro un pie, oh! Tiro el otro pie" (Les Chiens 126)

(cfr. Saint-Jonh Perse: "para mí, he retirado mis pies") (Elogios XIV)

-Empleo genérico de la palabra “grano” en la expresión “árbol a granos”(Chiens 147)

-la palabra "héler" con sentido de "llamar"

"Llamé mis dioses" (Chiens 94)

-empleo de la palabra "couresse" ("pulserilla”) con sentido de "culebra” (Moi, laminaire) 
-empleo de la palabra "tiaullé" en el poema "Internonce" (Moi, laminaire)1

La densidad de este recurso es significativa y no menos importante que la de SaintJohn Perse. Esto señala el carácter endógeno del imaginario cesairiano, que, como el del poeta guadalupano, recuerda que la lengua es la primera patria de todo escritor. Los análisis de Emile Yoyo en su ensayo Sain-John Perse ou le conteur (Saint-John Perse o el cuentista), donde se le atribuía una base creole al poeta guadalupano, al tiempo que se le negaba al poeta de la negritud, se encuentran, por lo tanto, invertidas.

En segundo lugar, cabe mostrar cómo, a través de la apreciación del genio creativo de su compatriota Gilbert Gratiant, Césaire, autor del prefacio de la re-edición de Fab Compè Zicaque (1996), ofrece una explicación de la relación que él mismo establece entre literatura y lengua. Su enfoque es particularmente interesante ya que, proponiendo exponer la práctica lingüística de Gratiant, analiza, en resumen, la suya. He aquí el fragmento del prefacio que me interesa:

Son realmente curiosas las relaciones de Gilbert Gratiant y la lengua creole. Gilbert Gratiant ciertamente no era un creolizante como uno pudiera imaginarlo. Tenía pocas ocasiones para hablar el creole. Lo hablaba mucho a la francesa y, aun así, lo escribía perfectamente. Es que anida en el espíritu y en el corazón alguna cosa que precede la lengua y la suscita: un estado del alma, un Stimmung como diría Heidegger, ese Stimmung que hace que Gilbert Gratiant no fuera hablante y tampoco empleara el creole, la lengua creole, sino que lo re-inventaba. No había encontrado el diccionario sino el genio que secreta la lengua, como el árbol que segrega su savia y cura sus heridas. El secreto de su eterna juventud de espíritu y de corazón lo llevaba preciosamente oculto en su interior: era para maravillarlo, para renovar su vitalidad, para alimentar su elocuencia que se confundía con su fortaleza, era una imagen desolada y volcánica (la misma por la cual vio desaparecer Saint-Pierre, de donde no se fue hasta la víspera de la erupción), era la imagen imperecedera e inolvidable de una Martinica infantil guardada en él, tan fresca como el primer día.

Para Césaire, aún si el creole de Gratiant no es el "gran creole", aún si tenía una pronunciación afrancesada, es un inmenso poeta creole. Dicho de otro modo, la poesía se burla del estrato del lector. La obsesión por el creole telúrico, por el creole basilecto como condición sine qua non de la autenticidad, se encuentra aquí puesta en duda. Este propósito puede parecer paradójico. Pero para Césaire, Gratiant no emplea simplemente la lengua. Como los alquimistas, que deben recomponer la materia, él re-inventaría la lengua gracias a una virtud que no es otra que la de la infancia, siempre inscrita en él y

1 N. de la T. Es importante resaltar que estas expresiones poéticas se derivan del creole y al traducirlas al español, muchas de ellas pierden su sentido. Es por esto que se han dejado en el dialecto original, con su significado aproximado en español entre comillas, para esclarecer el sentido de la palabra. 
constantemente reactivada. Cuando sabemos que Gratiant se fue de Martinica, siendo aún niño, esto nos permite imaginar la fuerza de esa inscripción. Podemos incluso formular la hipótesis de que semejante densidad fue posible solo porque al principio del siglo $\mathrm{XX}$, la lengua creole estaba aún demasiado áspera y no había iniciado el ciclo acelerado de la creolización, ese mecanismo que la acerca a la lengua francesa, de la cual recibe una creciente influencia hasta quedar absorbida. Hoy en día, un niño que se vaya de Martinica, corre el riesgo de no conservar una habilidad pasiva para hablar esta lengua. Pero, precisamente, para Césaire, la fuerza de la poesía de Gratiant no está relacionada con las diversas especificaciones de la palabra creole (fonológicas, léxicas, sintácticas) sino con el Verbo, que precisamente trasciende las simples producciones de la lengua. Un poeta, a los ojos de Césaire, no es solamente un ser dotado de sensibilidad; no es únicamente un hablante inscrito en una lengua dada; es alguien capaz de encontrar la correcta articulación entre su afectividad y una lengua cualquiera. Se produce entonces un milagro, el de la poesía.

El punto de vista de Césaire se desvía, de manera evidente, de una aproximación puramente ideológica del lenguaje, para fundar una conducta de tipo psico-estética. Esto evidencia una problemática que no es otra que la de la política de la escritura. Tal y como Césaire describe los mecanismos creativos de su obra, podemos deducir que instaura una política de la escritura diametralmente opuesta a la de Raphaël Confiant, otro escritor creolizante. El primero sería, de alguna manera, un alquimista capaz de "re-inventar" la lengua, y el segundo un "químico", buscando inventar la lengua, una lengua de síntesis, lo cual implica un denso recurso a la actividad neológica. Confiant, en tanto que escritor, tiene una tarea doble (en realidad prometeica y sisífica) que consiste, en una tensión de todos los instantes, en construir una lengua literaria aún inexistente en el movimiento mismo de su escritura. Por el contrario, Gratiant inserta, sin la menor tensión, un material no literario a la escrituralidad.

El análisis de Césaire es de una originalidad y pertinencia extraordinarias. Da cuenta, a partir de su propia experiencia, que la función esencial de la escritura es construir un lenguaje en la lengua, que el destino de todo escritor es su reencuentro singular con una lengua. De igual modo, también contesta con brío a todos los procesos de intención relacionados con el creole. No hay duda de que su lengua de creación literaria es el francés. Por una parte, porque esa lengua era la única que estaba disponible para sostener su grito y, por otra, porque no es suficiente el solo gritar para hacer obra de poesía. En otros términos, recordémoslo, para retomar una palabra del creole, su poesía se inscribe en una tradición literaria (que consta de Baudelaire, Rimbaud, Mallarmé, Apollinaire, etc). Es decir, pertenece al "hélé” y no al "wélélé”.

Traducción de Katerina Sierra 
BiBLIOGRAFÍA

Bickerton, Derek. "The Language Bioprogram Hypothesis." Behavioral and Brain Sciences 7 (1984): 173-221.

Ferguson, Charles A. "Diglossia". Word 15 (1959): 325-340.

Leiner, Jacqueline . "Entretien avec Aime Cesaire". Tropiques (1978): v-xxiv.

Yoyo, Emile. Sain-John Perse ou le conteur. Paris: Editions Bordas, 1971. 